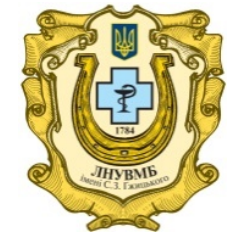

Ukrainian Journal of

Veterinary and Agricultural Sciences

http://ujvas.com.ua

Stepan Gzhytskyi National University of Veterinary Medicine and Biotechnologies Lviv

original article $\mid$ UDC 636.32/.38.09:614.448.57:595.132.6 | doi: 10.32718/ujvas1-2.04

Volume 1

Number 2

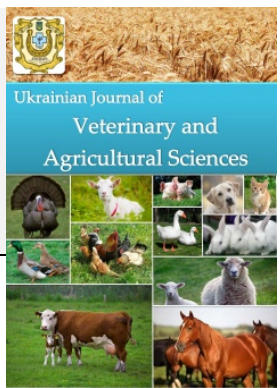

\title{
Disinvasive efficacy of chlorine-based preparations of domestic production for eggs of nematodes of the species Aonchotheca bovis parasitizing in sheep
}

V. Melnychuk, I. Yuskiv

Stepan Gzhytskyi National University of Veterinary Medicine and Biotechnologies Lviv, Pekarska Str., 50, Lviv, 79010, Ukraine

\begin{tabular}{|c|}
\hline $\begin{array}{l}\text { Article info } \\
\text { Received } 17.09 .2018 \\
\text { Received in revised form } \\
\quad 22.10 .2018 \\
\text { Accepted } 23.10 .2018\end{array}$ \\
\hline $\begin{array}{l}\text { Correspondence author } \\
\text { Vitaliy Melnychuk } \\
\text { Tel.: +38-066-674-78-09 } \\
\text { E-mail: melnychyk86@ukr.net }\end{array}$ \\
\hline $\begin{array}{l}\text { (C) } 2018 \text { Melnychuk V. et al. This is } \\
\text { an open-access article distributed } \\
\text { under the terms of the Creative } \\
\text { Commons Attribution License, } \\
\text { which permits unrestricted use, } \\
\text { distribution, and reproduction in any } \\
\text { medium, provided the original } \\
\text { author and source are credited. }\end{array}$ \\
\hline$(\mathrm{cc}) \mathrm{Br}^{\mathrm{B}}$ \\
\hline 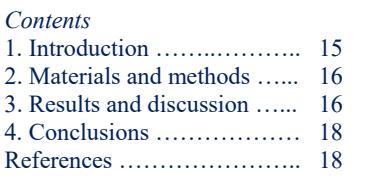 \\
\hline
\end{tabular}

\begin{abstract}
The paper presents the results of experimental researches on the determination of the disinvasion efficiency of chlorinated chemical preparations of domestic production of "Brovades-plus", "Bi-dez" and "Dezsans" of NPF "Brovafarma" (Ukraine). The conducted researches on the basis of the parasitology laboratory found that the studied disinfectants possess disinvasive properties in respect of non-invasive test culture of eggs of nematodes of the species Aonchotheca bovis (son Capillaria bovis) López-Neyra, 1947, isolated from gonads of females of worms. The dissimilar stability of eggs of capillaries to the effect of the tested agents in vitro is proved. The most effective disinfectant in the case of eggs of capillaries of the species A. bovis was the preparation "Dezsan". The high level of its disinvasive efficacy (DE - 91.14-100.0\%) was registered at the application of the preparation in $1.0-2.0 \%$ of the exposure concentration for 10-60 minutes. The chemicals "Bi-dez" and "Brovadez-plus" proved to be less effective in the relatively non-invasive test culture of A. bovis eggs. The high level of efficiency (DE 92.41-100.00\%) of the "Bi-dez" was achieved with its use at concentrations of $1.5 \%$ (exposure of 30 and $60 \mathrm{~min}$ ) and $2.0 \%$ (exposure of 10-60 minutes) The "Brovadez plus" preparation in vitro proved to be the least effective means of non-invasive test culture of nematode eggs of the species A. bovis, since a high level of disinvasive efficacy (DE - $100.00 \%$ ) was achieved only with the use of $2.0 \%$ solution per exposure 10-60 min. It was established that the experimentally tested chlorine-based means of domestic production resulted in the death of eggs in the culture in due to the destructive effect of the components of the preparations on the shell, the caps of eggs of the capillaries, as well as on the germ in the middle of the egg. In experimental cultures treated with the means, the destruction of the shell of the egg in the location of the caps, the exit of morulae outside, the cessation of development or shrinkage of the embryo and deformation of the egg shell were recorded.
\end{abstract}

Key words: disinvasion, disinvasion action, test-culture of eggs, sheep, Aonchotheca bovis

\section{Citation:}

Melnychuk, V., \& Yuskiv, I. (2018). Disinvasive efficacy of chlorine-based preparations of domestic production for eggs of nematodes of the species Aonchotheca bovis parasitizing in sheep. Ukrainian Journal of Veterinary and Agricultural Sciences, 1(2), $15-18$.

\section{Introduction}

Despite the large range of veterinary preparations in the modern drug market, invasive diseases of farm animals continue to grow on farms in both, Ukraine and other countries of the world (Bhutto et al., 2002; Velusamy et al., 2015; Boyko et al., 2016; Singh et al., 2016; Ola-Fadunsin and Ibitoye, 2017; Singh et al., 2017). Sheep farms of different forms of ownership have not become an exception. Among the most common parasitic diseases of sheep is the nematodosis of the gastrointestinal tract (Lindqvist et al., 2001; Borji et al., 2011; Boyko, 2015). This trend is explained by the developmental cycle of most nematodes, which occurs directly without the involvement of intermediates (Zajac, 2006; Romero et al., 2010).

It is known that the best conditions for the development of embryonic and post-embryonic forms of development of nematodes to the invasive stage are the superficial layers of the soil, litter, the floor, where the pathogen comes from the faeces during the act of defecation. The abovementioned is confirmed by the numerous studies of scientists who prove that the soil is one of the objects of the environment most vulnerable to contamination with invasive elements, including eggs of capillaries of the species Aonchotheca bovis (Capillaria bovis) López-Neyra, 1947 (Roeber et al., 2013; Stets and Voloshyna, 2016).

Contaminated with the stages of parasites, environmental objects are important in the proliferation and long-term preservation of exogenous stages of nematode development (Dubná et al., 2007; Yevstafieva et al., 2015).

In order to eliminate and prevent environmental contamination by invasive elements, there is a well-developed health improvement system that combines animal deworming and disinfestation of environmental objects (Naidoo et al., 2016; Moazeni et al., 2017). Experience shows that the main and the most effective among the avail- 
able methods of disinfestation is chemical, which involves the use of drugs based on various chemical compounds. According to the literature, the most effective are polycomotor drugs that contain several active substances (Zhu et al., 2013; Oliveira et al., 2013).

Taking into account already existing data of studies indicating the resistance of capillary eggs to the action of chemical agents, the issue of searching and approbation of modern disinvasive means of domestic production remains relevant for scientists, researchers and veterinary specialists (Yestafyeva and Natiahla, 2017).

Therefore, the purpose of our work was to study in a laboratory conditions the disinvasive properties of polycomorphous chlorine-containing preparations of domestic production for eggs of nematodes of the species Aonchotheca bovis parasitizing in sheep.

\section{Materials and methods}

The research was conducted during 2018 on the basis of the laboratory of the Parasitology and Veterinary Expertise Department of the Poltava State Agrarian Academy. Test cultures of non-invasive eggs of the nematodes of the species Aonchotheca bovis, obtained from gonads of females of helminths, were used as test cultures for the study of the disinfestation properties of chlorinated agents "Brovadezplus", "Bi-dez" and "Dezsan" of NPF "Brovafarma" (Ukraine), collected from the intestines of slaughtered sheep. The resulting mixture of eggs was washed with distilled water in separate Petri cups. The preparations were tested at concentrations of $0.5 \% ; 1.0 \% ; 1.5 \%$ and $2.0 \%$ at exposures of 10, 30 and 60 minutes.

A total of 24 Petri cups with cultures of eggs of nematodes were prepared. Separately, one control Petri cup was prepared with a non-invasive culture of eggs of capillaries that were not treated with preparations. To the pre-prepared mixture of capillary eggs was added the same amount of solution of the drug of a certain concentration. After suitable exposure, a mixture of eggs was washed four times in distilled water. Petri cups with a mixture of eggs of worms were placed in a thermostat at a temperature of $27{ }^{\circ} \mathrm{C}$ and cultured with periodic aeration until a mobile larva inside the egg appeared (27 days). Every five days, the cultures were examined under a microscope $(\times 100, \times 400)$. It were noted: the degree of development of eggs, taking into account changes in the shell, deformation of the embryos and the state of the development of larvae or their damage. Disinvasive efficacy (DE) of solutions of drugs was determined by the formula:

$$
D E=100-\left(Y_{1} / Y_{2}\right) \times 100, \%=100, \%
$$
ture;

where, $\mathrm{Y}_{1}-$ number of live eggs in the researched cul-

$\mathrm{Y}_{2}$ - number of live eggs in the control culture.

The assessment of disinvasive efficacy was carried out according to the indicators: a high level of efficiency - 90 $100 \%$, satisfactory $-60-89 \%$, unsatisfactory - up to $60 \%$.

\section{Results and discussion}

According to the results of the research, domestic preparations such as "Brovadez-plus", "Bi-dez" and "Dezsan" have disinvazial properties for non-invasive test cultures of nematode eggs of the species A. bovis (Table 1). At the same time, the best indicators of disinvasive efficacy in the in vitro experiments showed the disinfectant "Dezsan".

Thus, studying the disinvasive effect of "Dezsan" on non-invasive test culture of eggs of nematodes of the species A. bovis, it was found that the highest values of disinvasive efficiency (DE - 100.00\%) is given by the preparation at its use at $1.0 \%$ concentration at exposure of 60 minutes and $1.5 \%$ and $2.0 \%$ at exposure concentrations of $10-60$ minutes, respectively. It should be noted that the use of $1.0 \%$ solution of the preparation with a reduced exposure time (10 and $30 \mathrm{~min}$ ) had a high level of disinvasive efficacy (DE 91.14-93.67\%). The use of the product in the form of a $1.0 \%$ solution at exposures of $10-60 \mathrm{~min}$ resulted in a satisfactory level of disinvasive efficacy (DE - 73.42-86.08\%).

When establishing the disinvasive properties of the "Bidez" preparation, it has been documented that the drug has a disinvasive capacity for non-invasive test culture of A. bovis eggs, but the performance indicators compared to the "Dezsan" drug were slightly lower. Therefore a high level of disinvasive efficacy has been registered with the use of a solution in the form of $2 \%$ solution for all exposures (DE $100.00 \%$ ) and $1.5 \%$ solution at exposures 30 and 60 minutes (DE -92.41 and $100.00 \%$ respectively). The satisfactory level of disinvasive efficacy was recorded when the preparation was used in 0.5 and $1.0 \%$ exposure concentration for 10-60 minutes (DE - 62.03-69.62\% and 75.95-84.81\% respectively), as well as for a 10 -minute exposure at a concentration of $1.5 \%(\mathrm{DE}-89.87 \%)$.

\section{Table 1}

Disinvasive efficacy of chlorine-based preparations of domestic production in respect of egg culture nematodes of the species Aonchotheca bovis, \%

\begin{tabular}{|c|c|c|c|c|}
\hline \multirow{2}{*}{ Preparations } & \multicolumn{4}{|c|}{ Concentration of the drug } \\
\hline & $0.5 \%$ & $1.0 \%$ & $1.5 \%$ & $2.0 \%$ \\
\hline \multicolumn{5}{|c|}{ exposure of 10 minutes } \\
\hline "Dezsan" & 73.42 & 91.14 & 100.00 & 100.00 \\
\hline "Bi-dez" & 62.03 & 75.95 & 89.87 & 100.00 \\
\hline "Brovadez-plus" & 53.16 & 73.42 & 82.28 & 100.00 \\
\hline \multicolumn{5}{|c|}{ exposure of 30 minutes } \\
\hline "Dezsan" & 82.28 & 93.67 & 100.00 & 100.00 \\
\hline "Bi-dez" & 65.82 & 79.75 & 92.41 & 100.00 \\
\hline "Brovadez-plus" & 56.96 & 75.95 & 86.08 & 100.00 \\
\hline \multicolumn{5}{|c|}{ exposure of 60 minutes } \\
\hline "Dezsan" & 86.08 & 100.00 & 100.00 & 100.00 \\
\hline "Bi-dez" & 69.62 & 84.81 & 100.00 & 100.00 \\
\hline "Brovadez-plus" & 59.49 & 79.75 & 89.87 & 100.00 \\
\hline
\end{tabular}


The results of the research revealed that "Brovadez-plus" was the least effective in the non-invasive culture of nematode eggs of the A. bovis species, since the highest $(100.00 \%)$ disinvassive efficacy showed only at a concentration of $2.0 \%$ at exposures of 10,30 and 60 min Decreased preparation concentrations reduced its disinvasive efficacy. Therefore, the satisfactory level of disinvasive efficacy of the preparation is registered for the use of the preparation in the form of 1.0 and $1.5 \%$ solutions (DE - 73.42-89.87\%) for all proposed exposures. It should be noted that the use of the preparation in $0.5 \%$ concentration at exposures for $10-60$ minutes led to an unsatisfactory level of disinvasive efficacy (DE - 53.16-59.49\%).



$\boldsymbol{a}$



b

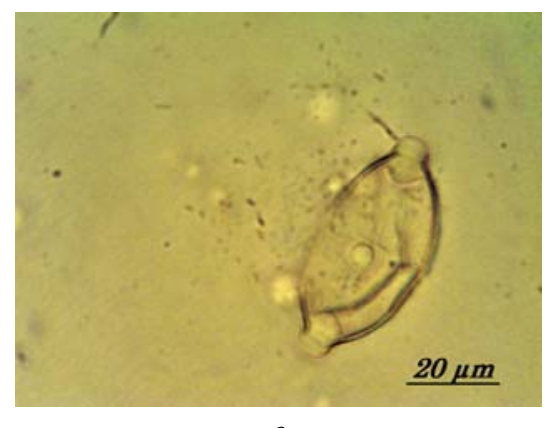

c

Fig. 1. Changes in the eggs of Aonchotheca bovis, isolated from gonads of females of worms, after application of chlorinecontaining substances: $\boldsymbol{a}$-destruction of the shell of the egg in the area of the caps and outlet morula out; $\boldsymbol{b}$ - termination of the development of the embryo and its shrinkage; $\boldsymbol{c}$-deformation of the shell of the egg

At the same time, in the control culture, in $79.0 \%$ of eggs of capillaries, until the end of the experiment, the formed larva (Fig. 2), which was actively moving under the influence of heat on it, was detected.

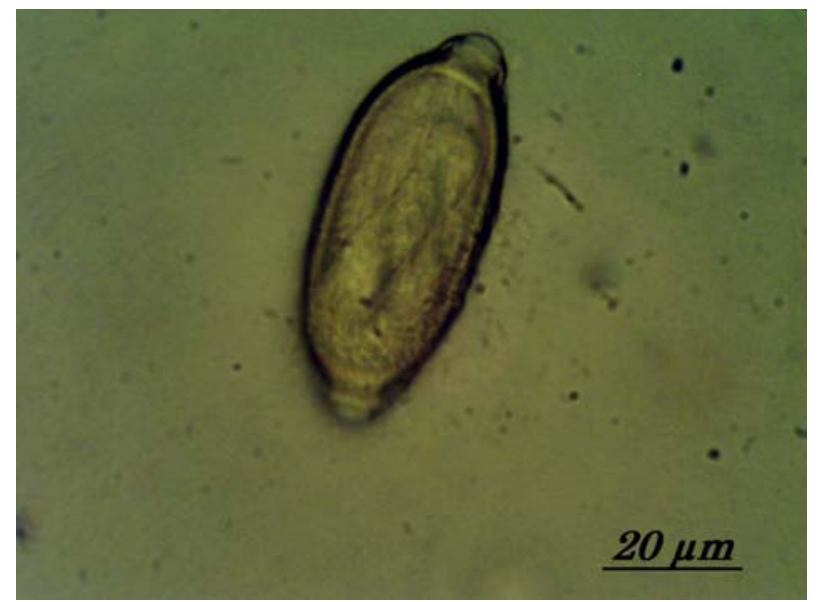

Fig. 2. Egg nematodes of the species Aonchotheca bovis of the control culture with the formed larvae at day 27 of the experiment

Consequently, experimental studies have found that the use of chlorine-containing disinvasive agents leads to the death of eggs of the capillaries of the species A. bovis, due to the destructive effect of the constituent components of preparations on the shell, eggs caps and their embryos.

According to the literature, a large number of researchers from many countries of the world, including Ukraine (Remmal et al., 2011; Boyko and Brygadyrenko, 2016), devoted to the study of disinfesive and larvocidal properties of disinfectants of various origins. The increased interest of scientists of the veterinary profile to work with modern and promising means possessing ocidal and larvocidal properties indicates a significant distribution of helminthic diseases of animals, as well as significant contamination of environmental objects by propagating stages of parasites (Dubná et al., 2007). Basically, as test objects for the study of disinfestation properties of disinfectants, researchers used nematodes of eggs of Ascaridita, since they have long been regarded as a benchmark for stability (Brewster et al., 2003). However, today, the high stability of not only the test cultures of the eggs of the ascarisate group, but also of other representatives of nematodes has been proved, which is confirmed experimentally (Oliveira et al., 2013; Melnychuk and Yuskiv, 2018). As the experience of scientists shows, the use of exogenous stages of the development of pathogens against which the struggle is being tested as a test object leads to the correct selection of means and modes of their application. This allows you to get high efficiency from the events. Therefore, our experimental research is relevant.

The conducted researches have established that chlorinecontaining preparations of domestic production have disinvazial properties, which is confirmed by the works of scientists (Berezovskyi and Nechiporenko, 2018). However, in our experiments, the nematode eggs of the species Aonchotheca bovis, a parasite of ruminants, were used for the first time in Ukraine as a test object. The modes of application of working solutions of preparations for the exogenous stages of the development of nematodes are determined and proposed. According to the literature (Yestafyeva and Natiahla, 2017), it is known that capillary eggs are resistant to most disinfectants, which is also consistent with our data. Thus, the data obtained in the experiments have an important theoretical and practical significance in the plan- 
ning and implementation of measures to control and prevent the capillarization of ruminants.

\section{Conclusions}

According to the results of in vitro studies it was determined that domestic preparations such as "Brovadez-plus", "Bi-dez" and "Dezsan" have disinvasive properties in noninvasive test cultures of nematodes of the species Aonchotheca bovis isolated from sheep. It was recorded that the most effective disinfectant $(91.14-100.0 \%)$ in the case of eggs of capillaries of the species A. bovis was the preparation "Dezsan" at concentrations of $1.0 \%, 1.5 \%$ and $2.0 \%$ at exposures of 10-60 minutes. "Bi-dez" and "Brovadez-plus" preparation were less effective in A. bovis egg culture because of higher levels of worker solutions $(1.5 \%, 2.0 \%$ and $2.0 \%$ ) were required for high levels of efficacy. The investigated means led to the death of capillary eggs from experimental test cultures, due to the destructive action of preparations on their shell, caps and embryos.

\section{References}

Berezovskyi, A.V., \& Nechiporenko, A.L. (2018). Determination of dezinvasion efficiency of a new disinfectant «Dezsan» for poultry eimeria. Scientific Messenger of Lviv National University of Veterinary Medicine and Biotechnologies, 20 (83), 401-404. doi: 10.15421/nvlvet8378.

Bhutto, B., Phullan, M.S., Rind, R., \& Soomro, A.H. (2002). Prevalence of gastro-intestinal helmi nths in buffalo calves. Journal of Biological Sciences, 2(1), 43-45. doi: $10.3923 /$ jbs.2002.43.45.

Borji, H., Raji, A., \& Naghibi, A. (2011). The comparative morphology of Marshallagia marshalli and Ostertagia occidentalis (Nematoda: Strongylida, Trichostrongylidae) by scanning electron microscopy. Parasitol. Res., 108, 13911395. doi: 10.1007/s00436-010-2186-2.

Boyko, O. (2015). Helmintofauna of sheep and goats in Dnipropetrovsk region. Vìsn. Dnìropetr. Univ. Ser. Bìol. Ekol., 6(2), 87-92. doi: 10.15421/021516.

Boyko, O., \& Brygadyrenko, V. (2016). The influence of the extent of infestation by helminths upon changes in body weight of sheep in Ukraine Visn. Dnipropetr. Unìv. Ser. Biol. Ekol., 24(2), 519-523. doi: 10.15421/011670.

Boyko, O., Zazharska, N., \& Brygadyrenko, V. (2016). The influence of the extent of infestation by helminths upon changes in body weight of sheep in Ukraine. Visn. Dnipropetr. Univ. Ser. Biol. Ekol., 24(1), 3-7. doi: 10.15421/011601.

Brewster, J., Oleszkiewicz, J., Bujoczek, G., Reimers, R. S., AbuOrf, M., Bowman, D., \& Fogarty, E. (2003). Inactivation of Ascaris suum eggs in digested and dewatered biosolids with lime and fly ash at bench scale and full scale. Journal of Environmental Engineering and Science, 2, 395-400. doi: 10.1139/S03-041.

Dubná, S., Langrová, I., Jankovská, I., Vadlejcha, J., Pekárb, S., Nápravníka, J., \& Fechtner, J. (2007). Contamination of soil with Toxocara eggs in urban (Prague) and rural areas in the Czech Republic. Veterinary Parasitology, 144(1-2), 81-86. doi: 10.1016/j.vetpar.2006.09.023.

Lindqvist, A., Ljungström, B. L., Nilsson, O., \& Waller, P.J. (2001). The dynamics, prevalence and impact of nematode infections in organically raised sheep in Sweden. Acta Vet. Scand., 42, 377-389. doi: 10.1186/1751-0147-42-377.

Melnychuk, V.V., \& Yuskiv, I.D. (2018). Studying of disinvasion action of the disinfectant Virosan for eggs Nematodes genus Trichuris parasitizing in sheep. Scientific Messenger of Lviv National University of Veterinary Medicine and Biotechnologies, 20(88), 16-23. doi: 10.32718/nvlvet8803.
Moazeni, M., Saadaty Ardakani, Z.S., Saharkhiz, M.J., Jalaei, J., Khademolhoseini, A.A., Shams Esfand Abad, S., \& Mootabi Alavi, A. (2017). In vitro ovicidal activity of Peganum harmala seeds extract on the eggs of Fasciola hepatica. Journal of Parasitic Diseases, 41(2), 467-472. doi: 10.1007/s12639-0160830-1.

Naidoo, D., Archer, C., Louton, B., \& Rodda, N. (2016). Testing household disinfectants for the inactivation of helminth eggs on surfaces and in spills during pit latrine emptying. Water S. A., 42(4), 560-570. doi: 10.4314/wsa.v42i4.06.

Ola-Fadunsin, S.D., \& Ibitoye, E.B. (2017). A retrospective evaluation of parasitic conditions and its associated risk factors in sheep and goats in Osun State, Nigeria. Sokoto J. Vet. Sci., 15(3), 15-24. doi: 10.4314/sokjvs.v15i3.3.

Oliveira, G.L., Vieira, T.M., Nunes, V.F., Ruas, M.O., Duarte, E.R., Moreira, D.L., Kaplan, M.A.C., \& Martins, E.R. (2014). Chemical composition and effcacy in the egg-hatching inhibition of essential oil of Piper aduncum against Haemonchus contortus from sheep. Revista Brasileira de Farmacognosia, 24(3), 288292. doi: 10.1016/j.bjp.2014.07.004.

Remmal, A., Achahbar, S., Bouddine, L., Chami, N., \& Chami, F. (2011). In vitro destruction of Eimeria oocysts by essential oils. Veterinary Parasitology. 182(2-4), 121-126. doi: 10.1016/j.vetpar.2011.06.002.

Roeber, F., Jex, A.R., \& Gasser, R.B. (2013). Impact of gastrointestinal parasitic nematodes of sheep, and the role of advanced molecular tools for exploring epidemiology and drug resistance - An Australian perspective. Parasites \& Vectors, 6(1), 153. doi: 10.1186/1756-3305-6-153.

Romero, N.C., Mendoza, G.D., Bustamante, L.P., Yanez, S., \& Ramirez, N. (2010). Contamination and viability of Toxocara $s p$. in feces collected from public parks, streets and dogs in Tejupilco at the subhumid tropic of Mexico. Journal of Animal and Veterinary Advances, 9(23), 2996-2999. doi: 10.3923/ javaa.2010.2996.2999.

Singh, E., Kaur, P., Singla, L.D., \& Bal, M.S. (2017). Prevalence of gastrointestinal parasitism in small ruminants in western zone of Punjab, India, Veterinary World, 10(1), 61-66. doi: 10.14202/vetworld.2017.61-66.

Singh, R., Bal, M.S., Singla, L.D. \& Kaur, P. (2016). Detection of anthelmintic resistance in sheep and goat against fenbendazole by faecal egg count reduction test. J. Parasit. Dis., 41(2), 1-4. doi: 10.1007/s12639-016-0828-8.

Stets, G., \& Voloshyna, N. (2016). Toxocara canis - bioindicator of parasitic soil contamination of technogenically transformed territories. The Advanced Science Journal, 2016 (03), 41-44. doi: 10.15550/ASJ.2016.03.041.

Velusamy, R., Rani, N., Ponnudurai, G., \& Anbarasi, P. (2015). Prevalence of intestinal and haemoprotozoan parasites of small ruminants in Tamil Nadu, India. Vet. World, 8(10), 1205-1209. doi: 10.14202/vetworld.2015.1205-1209.

Yestafyeva, V., \& Natiahla, I. (2017). Study of disinvasive properties of disinfectants to helminth eggs of chickens genus Capillaria. Bulletin of Zhytomyr National Agroecological University, 1(58), 128-132.

Yevstafieva, V.A., Yuskiv, I.D., \& Melnychuk, V.V. (2015). An Investigation of Embryo and Eggshell Development in Trichuris suis (Nematoda, Trichuridae) under Laboratory Conditions. Vestnik zoologii, 50(2), 173-178. doi: 10.1515/vzoo-20160020.

Zajac, A.M. (2006). Gastrointestinal Nematodes of Small Ruminants: Life Cycle, Anthelmintics, and Diagnosis. Veterinary Clinics of North America Food Animal Practice, 22(3), 529-541. doi: 10.1016/j.cvfa.2006.07.006.

Zhu, L., Dai, J.L., Yang, L., \& Qiu, J. (2013). In vitro ovicidal and larvicidal activity of the essential oil of Artemisia lancea against Haemonchus contortus (Strongylida). Veterinary Parasitology, 195(1-2), 112-117. doi: 10.1016/j.vetpar.2012.12.050. 